\title{
Supratentorial and Infratentorial Approaches to Pineal Surgery: A Database Analysis
}

\author{
David M. Rosenberg ${ }^{1}$ Brett W. Geever ${ }^{1} \quad$ Akash S. Patel $^{1}$ Anisse N. Chaker ${ }^{1}$ Abhiraj D. Bhimani ${ }^{1}$ \\ Pouyan Kheirkhah ${ }^{1}$ Jonathan G. Hobbs ${ }^{2}$ Darian R. Esfahani ${ }^{1}$ Ankit I. Mehta ${ }^{1}$
}

\footnotetext{
${ }^{1}$ Department of Neurosurgery, University of Illinois at Chicago, Chicago, Illinois, United States

2 Section of Neurosurgery, Department of Surgery, University of Chicago, Chicago, Illinois, United States
}

J Neurol Surg B 2019;80:364-370.
Address for correspondence Ankit I. Mehta, MD, Department of Neurosurgery, University of Illinois at Chicago, 912 W. Wood Street, 4N NPI, Chicago, IL 60612, United States (e-mail: ankitm@uic.edu).

\begin{abstract}
Keywords

- pineal gland

- supratentorial

- infratentorial

- database

- NSQIP

- outcomes

- tumor

Objectives Neoplasms involving the pineal gland are rare. When they do occur, tumor resection is anatomically challenging and is traditionally addressed by either a supratentorial or an infratentorial approach. To date, no large, multicenter studies have been performed that systematically analyze outcomes comparing these two approaches. This study aimed to evaluate outcomes for patients undergoing pineal neoplasm resection, comparing supratentorial and infratentorial approaches.

Design Retrospective database review.

Setting Multi-institutional database.

Participants From 2005 to 2016, 60 patients were identified, with 13 undergoing a supratentorial approach and 47 undergoing an infratentorial approach.

Main Outcome Measures Patient demographics, comorbidities, and 30-day postoperative outcomes were investigated using the American College of Surgeons National Surgical Quality Improvement Program database. Demographics, readmission, reoperation, and complication rates were analyzed and compared with previous studies.

Results Patient demographics were similar between these two groups. The overall complication rates for the supratentorial and infratentorial approaches were 30.8 and $17 \%$, respectively, and the difference was not statistically significant. The most common medical complications encountered were respiratory and hematological.

Conclusion As the first multi-institutional database analysis of approaches to the pineal gland, this study provides an analysis of patient demographics, comorbidities, and postoperative complications. After controlling for preoperative risk factors and demographic characteristics, no statistically significant differences in postoperative outcomes were found between infratentorial and supratentorial approaches. The mean readmission, reoperation, and complication rates were found to be $2.1,8.3$, and $20 \%$, respectively. The lack of significant difference between approaches suggests that clinical decision-making should depend upon anatomical considerations and physician preference, although the complications illustrated here may provide some preoperative guidance.
\end{abstract}

received

May 25, 2018

accepted after revision

September 10, 2018

published online

October 25, 2018 (c) 2019 Georg Thieme Verlag KG

Stuttgart · New York
DOI https://doi.org/

10.1055/s-0038-1675231. ISSN 2193-6331. 


\section{Introduction}

The pineal gland is approximately 10 to $14 \mathrm{~mm}$ in size and is located posterior to the third ventricle. ${ }^{1}$ This location can make the pineal gland difficult to approach surgically, ${ }^{2}$ and proximity to the third ventricle and aqueduct place patients at a risk of hydrocephalus and elevated intracranial pressure. ${ }^{3}$ Pineal gland tumors are rare in adults, representing less than $1 \%$ of all adult brain tumors. ${ }^{3}$ Pineal tumors are more common in adolescents and children, making up 3 to $11 \%$ of pediatric brain tumors. $^{3,4}$ It is hypothesized that hormonal changes during adolescence involving melatonin, follicle-stimulating hormone, and luteinizing hormone ${ }^{5}$ may contribute to the formation of many pineal gland tumors in adolescents. ${ }^{1}$ Due to the uncommon nature of pineal surgery and lack of reliable data comparing the efficacy of surgical approaches, decisions regarding surgical approach are largely determined by the preference and experience of the operating surgeon. ${ }^{6,7}$ Access to the pineal gland involves navigation around numerous large vascular structures including the vein of Galen. Although both anterior and posterior approaches are possible, posterior approaches are far more common. Posterior approaches are typically divided into supratentorial and infratentorial approaches, ${ }^{8}$ which are illustrated in -Fig. 1.

Supratentorial approaches, which include the transcallosal interhemispheric, occipital transtentorial, and transcortical transventricular approaches, ${ }^{6}$ allow for better visualization of the pineal region ${ }^{6}$ and are advantageous when addressing larger tumors dorsal to the vein of Galen ${ }^{8}$ or extending laterally. ${ }^{6}$ A disadvantage of this technique is that the surgeon must navigate around multiple cerebral veins, including the vein of Galen, making this approach more challenging and potentially hazardous. 9,10

The most frequent infratentorial approach to pineal gland tumors is the supracerebellar infratentorial approach and is more useful for small- or intermediate-sized tumors that lie below the vein of Galen. 3,6,11 The patient is typically placed in a seated or concord position for this surgery, allowing the cerebellum to slide downward under the force of gravity and creating a natural opening for the surgeon to approach the tumor. ${ }^{6}$ A major disadvantage of this approach is that patient positioning does not lend itself to ergonomic placement of the surgeon's hands and may lead to surgeon discomfort over prolonged cases. $^{8,9}$ Additionally, this patient position can lead to vascular complications such as air embolism. ${ }^{11}$

Previous research describing approaches to the pineal region has been limited to single-center and single surgeon studies. In this paper, we use an international, multi-institutional database to compare supratentorial and infratentorial approaches to pineal gland tumors to identify risk factors for readmission and reoperation.

\section{Methods}

\section{Data Acquisition and Patient Selection}

A retrospective review of the American College of Surgeons National Surgical Quality Improvement Program (ACSNSQIP) database was performed, querying data from 2005 to 2016 to identify patients undergoing surgery for resection of pineal gland tumors. The ACS-NSQIP is an international database featuring more than 600 institutions used to record an array of standard surgical outcomes with the goal of improving the quality of surgical practice, ${ }^{12}$ and it has been used in multiple neurosurgical studies examining surgical outcomes. ${ }^{13-20}$ Data in the NSQIP database are acquired directly from patient charts rather than through billing records by specialized data collectors at each institution and subject to regular quality control reviews to ensure site-to-site uniformity. The period of data collection begins before surgery and extends until 30 days after the

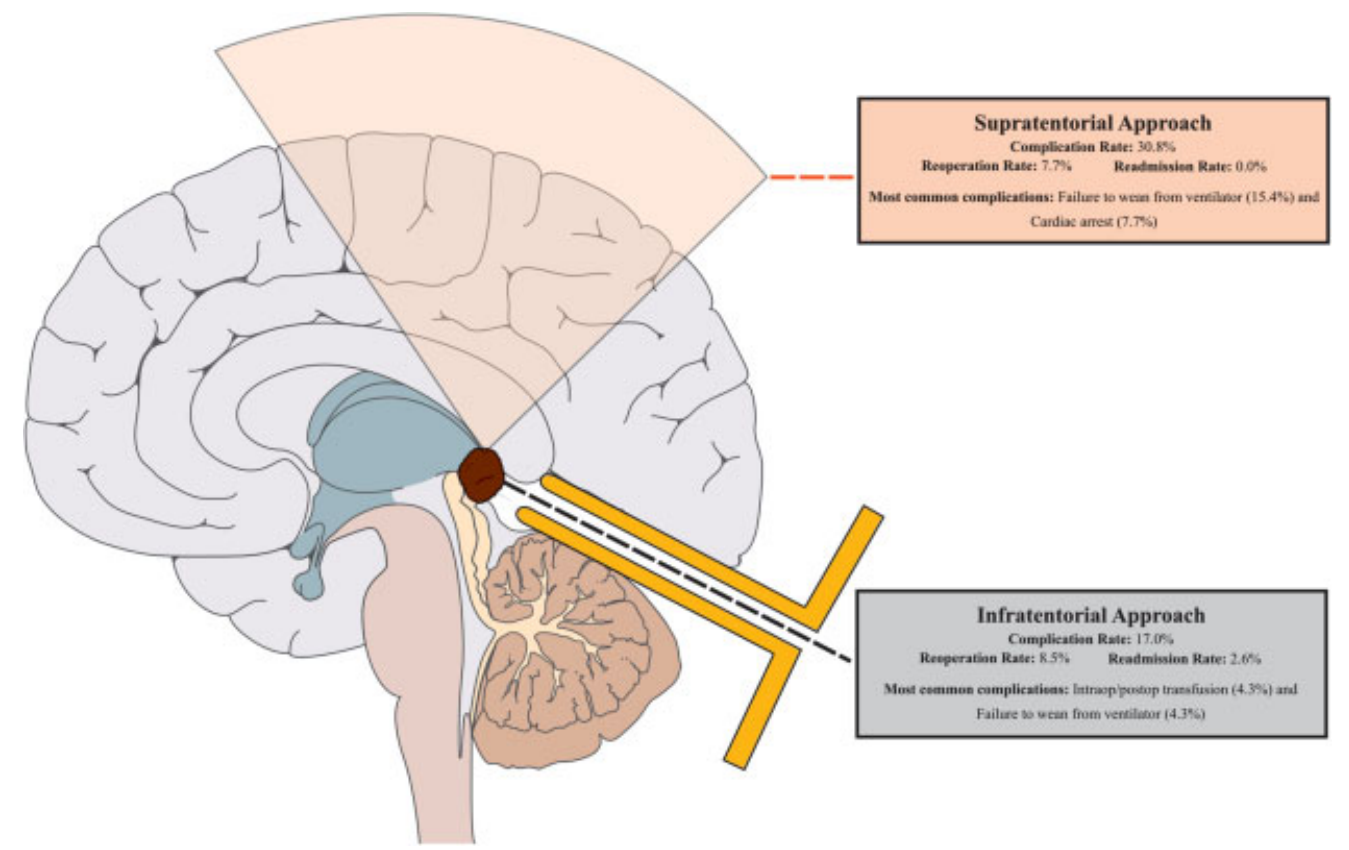

Fig. 1 Surgical approaches to the pineal gland. 
operation. $^{21}$ Surgical cases were included if coded with Current Procedural Terminology (CPT) codes 61510 (craniectomy, trephination, bone flap craniotomy; for excision of brain tumor, supratentorial, except for meningioma), 61518 (craniectomy for excision of brain tumor, infratentorial or posterior fossa; except meningioma, cerebellopontine angle tumor, or midline tumor at base of skull), 61521 (craniectomy for excision of brain tumor, infratentorial or posterior fossa; midline tumor at base of skull), or 61524 (craniectomy, infratentorial or posterior fossa, for excision or fenestration of cyst), and International Classification of Diseases (ICD)-9 codes 194.4 (malignant neoplasm of pineal gland), 227.4 (benign neoplasm of pineal gland), or 237.1 (neoplasm of uncertain behavior of pineal gland), or the corresponding ICD-10 codes C75.3, D35.4, or D44.5.

One patient meeting the inclusion criteria was excluded from this study due to the presence of preoperative sepsis. Patient selection, inclusion criteria, exclusion criteria, and definitions of the relevant CPT and ICD codes are described in the Supplementary Material. Study approval was obtained through the university's Institutional Review Board. A waiver for consent was granted as ACS-NSQIP data are deidentified and poses no risk to participants.

\section{Demographic and Outcome Variables}

Demographic data including sex, age, race, height, weight, functional status, and American Society of Anesthesiologists (ASA) class were collected. Age was separated into four categories: 18 to 35,35 to 55,55 to 75 , and $>75$. Body mass index (BMI) and obesity status were calculated based on patient height and weight, and BMI was separated into five categories: $<25,25$ to 30,30 to 35,35 to 40 , and $>40$. ASA class was stratified into classes 1 to 2 and classes 3 to 5 to assess preoperative patient fitness, and functional status was grouped into categories of independent and nonindependent.

For all patients, 30-day postoperative readmissions, reoperations, all postoperative and perioperative complications, and total length of hospital stay were evaluated. Complications studied included infections, respiratory, hematological and cardiovascular complications. Complications were included in this analysis if at least one patient experienced that complication.

\section{Statistical Analysis}

Analyses of variance were used to compare patient demographic characteristics with multiple categories, including race, age, and BMI. Chi-square tests were used to compare binary demographic characteristics, including gender, functional status, and ASA class. Fisher's exact test was used to compare all other patient demographic characteristics and to compare the univariate incidence of complications, reoperations, and readmissions between supratentorial and infratentorial approaches. Multivariable logistic regression was further used to compare the incidence of complications, reoperations, and readmissions between approaches using age, BMI, sex, ASA class, and smoking status as covariates. Statistical significance was set at $p<0.05$, and all statistical analysis was performed using R 3.3.2 (R Foundation, Vienna, Austria).

\section{Results}

\section{Demographics Comorbidities}

Demographic findings are summarized in -Table 1. Of the 60 patients meeting inclusion and exclusion criteria, 13 patients underwent a supratentorial approach and 47 underwent an infratentorial approach. This group included 30 males (50\%) and 30 females (50\%), with a trend toward supratentorial approaches in male patients (76.9\%; $p=0.058$ ). An average age of 29.7 years was noted for the supratentorial approach and 38.2 years for the infratentorial approach. No significant differences were noted between the groups for race, age, smoking status, ASA class, or functional status. Patients undergoing infratentorial surgeries were noted to have higher average BMI (28.9) versus their supratentorial counterparts (27), but this fell short of significance. There were no significant differences between the two approaches with respect to comorbidities, although there was a greater percentage of smokers in the supratentorial group (46.2\%) versus the infratentorial group $(21.3 \% ; p=0.088)$. Patient age and race were similar between the two groups. The supratentorial group had a tendency toward lower BMI scores as compared with the infratentorial group $(p=0.060)$.

\section{Surgical Outcomes and Complications}

Surgical outcomes and complications are summarized in - Table 2. Reoperation, readmission, and complications rates did not differ significantly between the two groups in univariate or multivariable analysis. The overall reoperation rate was $8.3 \%$, with one supratentorial patient requiring reoperation and four infratentorial patients requiring reoperation (7.7 and 8.5\%). Only three of the infratentorial patients' reasons for reoperation were recorded, and these included single cases of hematoma evacuation, shunt creation for hydrocephalus, and needle aspiration for pseudomeningocele. No patients from the supratentorial group required readmission, whereas one $(2.6 \%)$ patient from the infratentorial group required readmission for incisional site infection.

Postoperative complications were noted in $30.8 \%$ of supratentorial patients and $17 \%$ of infratentorial patients. The most frequent complications in the supratentorial group were respiratory in nature and entirely consisted of patients unable to be weaned from the ventilator within 48 hours ( $n=2 ; 15.4 \%)$. The most frequent complications in the infratentorial group were hematological and respiratory (both $n=3 ; 6.4 \%$ ), with the respiratory complications including two patients with failure to wean from the ventilator within 48 hours and one patient requiring reintubation. Infratentorial hematological complications included two patients who required transfusions and one patient with pulmonary embolism. The supratentorial group had a tendency toward more frequent respiratory complications in general and failure to wean from the ventilator in particular, but this trend did not reach significance. The mean length of stay of the entire population was 6.8 days, with no significant difference between the operative techniques. 
Table 1 Demographics for patients undergoing pineal surgery

\begin{tabular}{|c|c|c|c|c|c|}
\hline & & Total & Supratentorial & Infratentorial & $p$-Value \\
\hline \multirow[t]{3}{*}{ Total patients } & & 60 & 13 & 47 & \multirow[t]{3}{*}{0.058} \\
\hline & Male & $30(50 \%)$ & 10 (76.9\%) & 20 (42.6\%) & \\
\hline & Female & $30(50 \%)$ & $3(23.1 \%)$ & 27 (57.4\%) & \\
\hline \multirow[t]{4}{*}{ Race } & Black & $6(10 \%)$ & $3(23.1 \%)$ & $3(6.4 \%)$ & \multirow[t]{4}{*}{0.363} \\
\hline & White & 45 (75\%) & $8(61.5 \%)$ & 37 (78.7\%) & \\
\hline & Asian & $2(3.3 \%)$ & $1(7.7 \%)$ & $1(2.1 \%)$ & \\
\hline & Unknown & $7(11.7 \%)$ & $1(7.7 \%)$ & $6(12.8 \%)$ & \\
\hline \multirow[t]{5}{*}{$\mathrm{Age}^{\mathrm{a}}$} & Mean \pm SD & $36.4 \pm 13.7$ & $29.7 \pm 13.6$ & $38.2 \pm 13.1$ & \multirow[t]{5}{*}{0.168} \\
\hline & $16-35$ & 31 (54.4\%) & $9(75 \%)$ & 22 (48.9\%) & \\
\hline & $35-55$ & 18 (31.6\%) & $2(16.7 \%)$ & $16(35.6 \%)$ & \\
\hline & $55-75$ & $8(14 \%)$ & $1(8.3 \%)$ & $7(15.6 \%)$ & \\
\hline & $>75$ & $0(0 \%)$ & $0(0 \%)$ & $0(0 \%)$ & \\
\hline \multirow[t]{6}{*}{$\mathrm{BMI}^{\mathrm{b}}$} & Mean \pm SD & $28.5 \pm 6$ & $27 \pm 4.7$ & $28.9 \pm 6.3$ & \multirow[t]{6}{*}{0.060} \\
\hline & $<25$ & 17 (28.8\%) & $5(38.5 \%)$ & $12(26.1 \%)$ & \\
\hline & $25-30$ & 23 (39\%) & $4(30.8 \%)$ & 19 (41.3\%) & \\
\hline & $30-35$ & $10(16.9 \%)$ & $3(23.1 \%)$ & $7(15.2 \%)$ & \\
\hline & $35-40$ & $6(10.2 \%)$ & $1(7.7 \%)$ & $5(10.9 \%)$ & \\
\hline & $>40$ & $3(5.1 \%)$ & $0(0 \%)$ & $3(6.5 \%)$ & \\
\hline \multirow[t]{2}{*}{ Obesity $^{\mathrm{b}}$} & Not Obese & $40(67.8 \%)$ & 9 (69.2\%) & 31 (67.4\%) & \multirow[t]{2}{*}{1} \\
\hline & Obese & 19 (32.2\%) & $4(30.8 \%)$ & 15 (32.6\%) & \\
\hline Smoker & & 16 (26.7\%) & $6(46.2 \%)$ & $10(21.3 \%)$ & 0.088 \\
\hline Hypertension & & $14(23.3 \%)$ & $2(15.4 \%)$ & 12 (25.5\%) & 0.713 \\
\hline Diabetes & & $5(8.3 \%)$ & $2(15.4 \%)$ & $3(6.5 \%)$ & 0.295 \\
\hline \multirow[t]{2}{*}{ ASA class } & $1-2$ & 24 (40\%) & $5(38.5 \%)$ & 19 (40.4\%) & \multirow[t]{2}{*}{1} \\
\hline & $3-5$ & $36(60 \%)$ & $8(61.5 \%)$ & 28 (59.6\%) & \\
\hline \multirow[t]{2}{*}{ Functional status } & Independent & 59 (98.3\%) & $12(92.3 \%)$ & 47 (100\%) & \multirow[t]{2}{*}{0.217} \\
\hline & Partially/Totally Dependent & $1(1.7 \%)$ & $1(7.7 \%)$ & $0(0 \%)$ & \\
\hline
\end{tabular}

Abbreviations: ASA, American Society of Anesthesiologists; BMI, body mass index; SD, standard deviation.

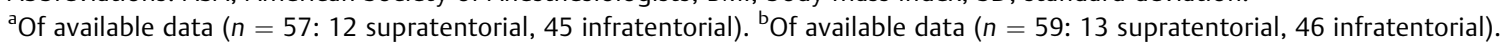

\section{Discussion}

Previous studies addressing pineal approaches have been limited to single-center, often single surgeon samples, which can lead to bias. These studies are summarized in - Table 3. . $^{3,4,8-10,22-26}$ This study is one of the first to use a multi-institutional database to explore the risk profile of the two most common pineal surgical approaches: infratentorial and supratentorial. The infratentorial and supratentorial groups were similar in demographics, preoperative comorbidities, and complication profiles, although there was a trend toward male sex and positive smoking status in the supratentorial group. The majority (60\%) of NSQIP patients presented with an ASA class between 3 and 5, indicating advanced disease. More than half (54.4\%) of the patients in the NSQIP cohort were between 16 and 35 years of age. This is expected as most patients with pineal tumors are young, with children being 10 times more likely than adults to be diagnosed with a pineal tumor. ${ }^{3}$
Two common types of tumors that occur in the pineal region are pineal cell tumors and germ cell tumors. Germ cell tumors are known to make up a significant portion of tumors found in the pineal region, with multiple studies reporting rates of 31 to $41 \%$ of pineal region tumors being of germ cell origin. $^{3,9,22}$ The peak incidence of germ cell tumors occurs between the ages of 15 and 19 years, likely secondary to hormonal changes. ${ }^{5}$ Germ cell tumors are also much more likely to be found in males than females, with past studies reporting male-to-female ratios ranging from 5:1 to $22: 1 .^{27}$ Parenchymal cell tumors have a wider age range, with most tumors occurring in patients younger than 47 , and possibly have a small female sex preference. ${ }^{18,28}$ As germ cell tumors are much more common in males and primary pineal cell tumors show a small female sex preference, ${ }^{18,27,28}$ it was expected that a majority of patients in the NSQIP cohort would be male. No sex difference was noted, however, which may be attributable to germ cell sensitivity to radiation and 
Table 2 Surgical outcomes and complications

\begin{tabular}{|c|c|c|c|c|c|c|}
\hline \multicolumn{2}{|c|}{ Operative outcome } & Total & Supratentorial & Infratentorial & $\begin{array}{l}\text { Univariate } \\
p \text {-value }\end{array}$ & $\begin{array}{l}\text { Multivariable } \\
p \text {-value }\end{array}$ \\
\hline \multicolumn{2}{|c|}{ Total complications } & $12(20 \%)$ & $4(30.8 \%)$ & $8(17 \%)$ & 0.271 & 0.971 \\
\hline Readmission $^{\mathrm{a}}$ & & $1(2.1 \%)$ & $0(0 \%)$ & $1(2.6 \%)$ & 1 & 1 \\
\hline \multicolumn{2}{|l|}{ Return to the OR } & $5(8.3 \%)$ & $1(7.7 \%)$ & $4(8.5 \%)$ & 1 & 1 \\
\hline \multicolumn{2}{|c|}{ Complications: infection } & $1(1.7 \%)$ & $0(0 \%)$ & $1(2.1 \%)$ & 1 & $>0.99$ \\
\hline & $\begin{array}{l}\text { Deep incisional } \\
\text { surgical site }\end{array}$ & $1(1.7 \%)$ & $0(0 \%)$ & $1(2.1 \%)$ & 1 & $>0.99$ \\
\hline \multicolumn{2}{|c|}{ Complications: respiratory } & $5(8.3 \%)$ & $2(15.4 \%)$ & $3(6.4 \%)$ & 0.295 & $>0.99$ \\
\hline & Unplanned reintubation & $1(1.7 \%)$ & $0(0 \%)$ & $1(2.1 \%)$ & 1 & $>0.99$ \\
\hline & $\begin{array}{l}\text { Failure to wean from } \\
\text { the ventilator }\end{array}$ & $4(6.7 \%)$ & $2(15.4 \%)$ & $2(4.3 \%)$ & 0.202 & $>0.99$ \\
\hline \multicolumn{2}{|c|}{ Complications: hematological } & $4(6.7 \%)$ & $1(7.7 \%)$ & $3(6.4 \%)$ & 1 & $>0.99$ \\
\hline & Pulmonary embolism & $1(1.7 \%)$ & $0(0 \%)$ & $1(2.1 \%)$ & 1 & $>0.99$ \\
\hline & $\begin{array}{l}\text { Intra-/postoperative } \\
\text { transfusion }\end{array}$ & $3(5 \%)$ & $1(7.7 \%)$ & $2(4.3 \%)$ & 1 & $>0.99$ \\
\hline \multicolumn{2}{|c|}{ Complications: cardiovascular } & $2(3.3 \%)$ & 1 (7.7\%) & $1(2.1 \%)$ & 1 & 1 \\
\hline & Cardiac arrest & $1(1.7 \%)$ & $1(7.7 \%)$ & $0(0 \%)$ & 1 & 1 \\
\hline & Myocardial infarction & $1(1.7 \%)$ & $0(0 \%)$ & $1(2.1 \%)$ & 1 & 1 \\
\hline \multirow{3}{*}{$\begin{array}{l}\text { Hospital length } \\
\text { of stay (days) }\end{array}$} & $0-5$ & $36(75 \%)$ & $6(46.2 \%)$ & $30(66.7 \%)$ & & \\
\hline & $5-10$ & $13(27.1 \%)$ & $4(30.8 \%)$ & $9(20 \%)$ & & \\
\hline & $>10$ & $9(18.8 \%)$ & $3(23.1 \%)$ & $6(13.3 \%)$ & & \\
\hline \multicolumn{2}{|c|}{ Mean hospital length of stay \pm SD } & $6.8 \pm 8.4$ & $8.5 \pm 9.2$ & $6.3 \pm 8.1$ & 0.412 & 0.669 \\
\hline
\end{tabular}

Abbreviations: OR, operating room; SD, standard deviation.

${ }^{\mathrm{a}}$ Of available data ( $n=48: 10$ supratentorial, 38 infratentorial). ${ }^{\mathrm{b}}$ Of available data ( $n=58: 13$ supratentorial, 45 infratentorial). ${ }^{\mathrm{c}} \mathrm{Adjusting}$ for the following variables: age, body mass index, American Society of Anesthesiologists class, and smoking status.

chemotherapy. This amenability to nonsurgical treatment may have obviated the need for resection, causing an underrepresentation in the NSQIP data.

\section{Outcomes of Infratentorial and Supratentorial Approaches}

Postoperative complications in the NSQIP cohort were severe in some cases and included myocardial infarction, cardiac arrest, intraoperative/postoperative transfusion, pulmonary embolism, failure to wean from the ventilator, and unplanned intubation. The incidences of pulmonary embolism and myocardial infarction were low, each occurring in single, separate patients, both of whom underwent an infratentorial procedure. Infratentorial procedures carry an elevated risk of air embolus while performed in the seated position, ${ }^{11}$ placing the patient at a risk of pulmonary embolism or myocardial infarction. The risks associated with the supratentorial approach involve the difficult nature of operating around the deep cerebral veins, and possible disruptions of these veins carry an elevated risk of bleeding or cortical damage., ${ }^{9,10}$ The case series by Qi et al that primarily consisted of patients undergoing an occipital transtentorial approach reported permanent hemianopsia in $3.5 \%$ of all patients, likely due to cortical injury from retraction or venous infarction during surgery.
While the risk of bleeding may be theoretically higher for supratentorial patients, there still remains a bleeding risk in patients undergoing an infratentorial procedure. The NSQIP data demonstrates that there were patients who required transfusion in both the supratentorial and infratentorial groups, suggesting that surgeons must be aware of bleeding risks in patients for both approaches.

A supratentorial approach was also used less often, representing only $21.7 \%$ of cases in the cohort. One explanation for this low rate of use can be attributed to the risks associated with operating around the vein of Galen and its branches. ${ }^{29}$ By contrast, pineal exposure in the infratentorial supracerebellar approach is typically inferior to the vein of Galen, potentially reducing the risk of bleeding ${ }^{9}$ and limiting brain retraction. ${ }^{8}$ Interestingly, the NSQIP data did not demonstrate a difference in overall transfusion rate for the infratentorial approach when compared with the supratentorial approach.

\section{Decision-Making Strategies}

Two disadvantages of the infratentorial supracerebellar approach are a higher risk of air embolism and an ergonomically disadvantageous hand position for the surgeon when this procedure is performed with the patient in the sitting 
Table 3 Literature review of pineal surgeries

\begin{tabular}{|c|c|c|c|c|c|c|c|}
\hline Authors & Year & $\begin{array}{l}\text { Data } \\
\text { collection }\end{array}$ & $\begin{array}{l}\text { Number } \\
\text { patients }\end{array}$ & Approaches & Study population & $\begin{array}{l}\text { Complication } \\
\text { rate }(\%)\end{array}$ & $\begin{array}{l}\text { Mortality } \\
\text { rate (\%) }\end{array}$ \\
\hline $\begin{array}{l}\text { Rosenberg et al } \\
\text { (current study) }\end{array}$ & 2018 & 2005-2016 & 60 & $\begin{array}{l}\text { Infratentorial and } \\
\text { supratentorial }\end{array}$ & $\begin{array}{l}\text { Multicenter, } \\
\text { multiple surgeons }\end{array}$ & 20 & 0 \\
\hline Hernesniemi et al & 2018 & $1980-2007$ & $\begin{array}{l}119 \\
(107)^{a}\end{array}$ & $\begin{array}{l}\text { Infratentorial and } \\
\text { supratentorial }\end{array}$ & $\begin{array}{l}\text { Two centers, } \\
\text { single surgeon }\end{array}$ & $21.5^{b}$ & 0 \\
\hline Kotwica et al & 2017 & & 22 & Infratentorial & $\begin{array}{l}\text { Single center, } \\
\text { single surgeon }\end{array}$ & 0 & 0 \\
\hline $\begin{array}{l}\text { Choque- } \\
\text { Velasquez et al }\end{array}$ & 2017 & $2012-2015$ & 24 & Infratentorial & $\begin{array}{l}\text { Single center, } \\
\text { single surgeon }\end{array}$ & 4.2 & 0 \\
\hline Qi et al & 2014 & $2000-2011$ & 143 & $\begin{array}{l}\text { Infratentorial and } \\
\text { supratentorial }\end{array}$ & $\begin{array}{l}\text { Single center, } \\
\text { multiple surgeon }\end{array}$ & $18.2^{\mathrm{b}}$ & 0.7 \\
\hline Oliveira et al & 2013 & 1993-2012 & 32 & Infratentorial & Single surgeon & $56.3^{b}$ & 0 \\
\hline $\begin{array}{l}\text { Konovalov and } \\
\text { Pitskhelauri }\end{array}$ & 2003 & 1976-1999 & 244 & $\begin{array}{l}\text { Infratentorial and } \\
\text { supratentorial }\end{array}$ & $\begin{array}{l}\text { Single center, } \\
\text { multiple surgeons }\end{array}$ & $54.5^{\mathrm{b}}$ & 8.2 \\
\hline Little et al & 2001 & & 57 & $\begin{array}{l}\text { Infratentorial and } \\
\text { supratentorial }\end{array}$ & $\begin{array}{l}\text { Single center, } \\
\text { three surgeons }\end{array}$ & & \\
\hline Fauchon et al & 1998 & 1972-1997 & $47(44)^{\mathrm{a}}$ & & $\begin{array}{l}\text { Multicenter, } \\
\text { multiple surgeons }\end{array}$ & & 15.9 \\
\hline Cho et al & 1998 & 1986-1995 & $48(33)^{a}$ & Supratentorial & Single center & $48.5^{b}$ & 0 \\
\hline Bruce and Stein & 1995 & & 154 & $\begin{array}{l}\text { Infratentorial and } \\
\text { supratentorial }\end{array}$ & $\begin{array}{l}\text { Single center, } \\
\text { two surgeons }\end{array}$ & $22.7^{\mathrm{b}, \mathrm{c}}$ & 3.9 \\
\hline
\end{tabular}

${ }^{\mathrm{a}}$ Number in parenthesis is the number of patients considered for rate calculations. ${ }^{\mathrm{b}}$ Complication rates included complications different than those reported in this study. ${ }^{\circ}$ Complication rates included only complications leading to permanent morbidity.

position. It has been suggested that alternative surgical and positioning techniques may help minimize these issues. A recently published review on pineal surgeries suggests that the praying sitting position, an alternate to the traditional seated patient position, may reduce the risk of air embolism. The authors of this review used this position in 56 patients undergoing an infratentorial supracerebellar pineal surgery and had no instances of clinically significant air embolism. This position involves tilting the patient's head and upper body at a steeper downward angle during the surgery, and the authors claim that the position is also more comfortable for the surgeon's hands. ${ }^{30}$ If these two primary disadvantages of the infratentorial supracerebellar approach can be mitigated, it would make the infratentorial supracerebellar approach even more appealing for treating pineal tumors given the comparable complication rates reported here and less complex nature of the approach. However, the infratentorial supracerebellar approach may be contraindicated in certain situations such as in larger tumors. ${ }^{9,23}$ In cases with larger tumors, the supratentorial approaches may provide a better view of the tumor, ${ }^{9}$ and the increased risk of complications associated with supratentorial approaches may be justified. However, when using a supratentorial approach, the surgeon should be cognizant of a somewhat increased risk of vasculature compromise.

\section{Limitations}

Large database studies carry inherent limitations. While relevant data, including risk factors and rates of readmission and reoperation, are included, the database is limited to outcomes within 30 days of surgery and does not report specific neurologic deficits postoperatively such as visual changes and memory disturbances. Additionally, the database is limited by the lack of facility identifiers, hospital location (community vs academic), site of service (inpatient vs outpatient), presence or absence of residents, and institution pineal volume. Another limitation is the relatively small number of cases, which may have adversely affected the ability to extrapolate definite operational differences between the two approaches examined. However, given the rare nature of pineal tumors, this is somewhat expected as an inherent obstacle in analysis. Finally, the NSQIP data only reflects institutions that participate in the ACS-NSQIP (689 as of January 2018) and may be subject to selection bias since these institutions are not required to report all consecutive cases. This may somewhat limit the generalizability of the findings. Despite these limitations, the NSQIP represents a broad surgeon population and allows for comparison of cases across institutions, decreasing the biases inherent to single-center or single-surgeon series.

\section{Conclusion}

Pineal gland tumors are rare in adults, and the anatomical location of the pineal region makes these tumors difficult to approach surgically. This study aims to analyze surgical outcomes of infratentorial and supratentorial approaches to the pineal gland. After controlling for preoperative risk 
factors and demographic characteristics between the infratentorial and supratentorial approaches, no statistically significant differences in postoperative outcomes were detected when comparing the two approaches. Analysis of the data revealed a mean readmission rate of $2.1 \%$, return to the operating room rate of $8.3 \%$, and complication rate of $20 \%$. Without a statistically significant difference between the approaches, in situations where either strategy is reasonable, the evidence from this study suggests that either approach can be selected at the surgeon's discretion, although the surgeon should be aware of the possible risks associated with each approach. These findings provide a "snapshot" of contemporary pineal gland surgery and may serve as a useful benchmark for future studies.

\section{Funding}

The authors have not received any funding for this work.

\section{Conflict of Interest}

The authors disclose that there are no conflicts of interest.

\section{References}

1 Mottolese C, Szathmari A, Beuriat P-A. Incidence of pineal tumours. A review of the literature. Neurochirurgie 2015;61(2-3):65-69

2 Choudhry O, Gupta G, Prestigiacomo CJ. On the surgery of the seat of the soul: the pineal gland and the history of its surgical approaches. Neurosurg Clin N Am 2011;22(03):321-333, vii

3 Konovalov AN, Pitskhelauri DI. Principles of treatment of the pineal region tumors. Surg Neurol 2003;59(04):250-268

4 Cho B-K, Wang K-C, Nam D-H, et al. Pineal tumors: experience with 48 cases over 10 years. Childs Nerv Syst 1998;14(1-2):53-58

5 Kieran MW, Walker D, Frappaz D, Prados M. Brain tumors: from childhood through adolescence into adulthood. J Clin Oncol 2010; 28(32):4783-4789

6 Kennedy BC, Bruce JN. Surgical approaches to the pineal region. Neurosurg Clin N Am 2011;22(03):367-380, viii

7 Chen L, Mao Y. Consensuses and controversies on pineal tumor surgery. World Neurosurg 2010;74(4-5):446-447

8 Little KM, Friedman AH, Fukushima T. Surgical approaches to pineal region tumors. J Neurooncol 2001;54(03):287-299

9 Qi S, Fan J, Zhang XA, Zhang H, Qiu B, Fang L. Radical resection of nongerminomatous pineal region tumors via the occipital transtentorial approach based on arachnoidal consideration: experience on a series of 143 patients. Acta Neurochir (Wien) 2014;156 (12):2253-2262

10 Hernesniemi J, Romani R, Albayrak BS, et al. Microsurgical management of pineal region lesions: personal experience with 119 patients. Surg Neurol 2008;70(06):576-583

11 Hart MG, Santarius T, Kirollos RW. How I do it-pineal surgery: supracerebellar infratentorial versus occipital transtentorial. Acta Neurochir (Wien) 2013;155(03):463-467

12 Shiloach M, Frencher SK Jr, Steeger JE, et al. Toward robust information: data quality and inter-rater reliability in the American College of Surgeons National Surgical Quality Improvement Program. J Am Coll Surg 2010;210(01):6-16

13 Murphy M, Gilder H, McCutcheon BA, et al. Increased operative time for benign cranial nerve tumor resection correlates with increased morbidity postoperatively. J Neurol Surg B Skull Base 2016;77(04):350-357

14 Esfahani DR, Shah H, Arnone GD, Scheer JK, Mehta AI. Lumbar discectomy outcomes by specialty: a propensity-matched analysis of 7,464 patients from the ACS-NSQIP database. World Neurosurg 2018;18:e865-e870

15 Bhimani AD, Denyer S, Esfahani DR, Zakrzewski J, Aguilar TM, Mehta AI. Surgical complications in intradural extramedullary spinal cord tumors - an ACS-NSQIP analysis of spinal cord level and malignancy. World Neurosurg 2018;117(00):e290-e299

16 Chaker AN, Bhimani AD, Esfahani DR, et al. Epidural Abscess: a propensity analysis of surgical treatment strategies. Spine 2018 (e-pub ahead of print). . Doi: doi:10.1097/BRS.0000000000002747

17 Chiu RG, Hobbs J, Esfahani DR, et al. Anterior versus posterior approach for thoracic corpectomy: an analysis of risk factors, outcomes, and complications. World Neurosurg 2018;116:e723-e732

18 Bhimani AD, Esfahani DR, Denyer S, et al. Adult Chiari I malformations: an analysis of surgical risk factors and complications using an international database. World Neurosurg 2018;115:e490-e500

19 Arnone GD, Esfahani DR, Papastefan S, et al. Diabetes and morbid obesity are associated with higher reoperation rates following microvascular decompression surgery: an ACS-NSQIP analysis. Surg Neurol Int 2017;8:268

20 Arnone GD, Esfahani DR, Wonais M, et al. Surgery for cerebellar hemorrhage: a National Surgical Quality Improvement Program database analysis of patient outcomes and factors associated with 30-day mortality and prolonged ventilation. World Neurosurg 2017;106:543-550

21 American College of Surgeons. . About ACS NSQIP. http://www.facs. org/quality-programs/acs-nsqip/about. Accessed July 28, 2018

22 Bruce JN, Stein BM. Surgical management of pineal region tumors. Acta Neurochir (Wien) 1995;134(3-4):130-135

23 Fauchon F, Jouvet A, Paquis P, et al. Parenchymal pineal tumors: a clinicopathological study of 76 cases. Int J Radiat Oncol Biol Phys 2000;46(04):959-968

24 Kotwica Z, Saracen A, Kasprzak P. Keyhole surgery of pineal area tumors - personal experience in 22 patients. Transl Neurosci 2017;8:207-210

25 Choque-Velasquez J, Colasanti R, Resendiz-Nieves JC, et al. Supracerebellar infratentorial paramedian approach in Helsinki neurosurgery: cornerstones of a safe and effective route to the pineal region. World Neurosurg 2017;105:534-542

26 Oliveira J, Cerejo A, Silva PS, Polónia P, Pereira J, Vaz R. The infratentorial supracerebellar approach in surgery of lesions of the pineal region. Surg Neurol Int 2013;4:154

27 Parker JJ, Waziri A. Preoperative evaluation of pineal tumors. Neurosurg Clin N Am 2011;22(03):353-358, vii-viii

28 Dahiya S, Perry A. Pineal tumors. Adv Anat Pathol 2010;17(06): 419-427

29 Yamamoto I, Kageyama N. Microsurgical anatomy of the pineal region. J Neurosurg 1980;53(02):205-221

30 Choque-Velasquez J, Colasanti R, Resendiz-Nieves JC, et al. Praying sitting position for pineal region surgery: an efficient variant of a classic position in neurosurgery. World Neurosurg 2018;113: e604-e611 